\title{
Benefits of SenseCam Review on Neuropsychological Test Performance
}

\author{
Ana R. Silva, MSc, Salomé Pinho, PhD, Luís M. Macedo, PhD, Chris J. Moulin, PhD
}

Background: One of the core applications of Microsoft's SenseCam is memory rehabilitation. Research has shown that it is an effective memory aid that can cue episodic memories. However, the extent to which SenseCam might improve aspects of memory beyond merely re-presenting forgotten events and locations has not been assessed.

Purpose: In line with neuroimaging and anecdotal reports, this study aimed to investigate the hypothesis that SenseCam review would enhance cognitive function more generally.

Methods: Participants were 15 healthy younger adults and 14 healthy older adults who wore a SenseCam for 3 days, and wrote a diary for another 3 days (control). In each of these conditions, participants completed a comprehensive neuropsychological battery immediately following review of the pictures or reading of the diary. Data for this study were collected from October to December 2011 and analyzed from January to March 2012.

Results: Both young and older adults showed higher performance on most measures used in this study immediately following SenseCam review. Effects were largest for memory and executive function tasks, whereas speed of processing was not affected.

Conclusions: SenseCam review seems to act as a cognitive stimulant in the short term, with higher neuropsychological assessment scores following SenseCam review compared to re-reading a diary.

(Am J Prev Med 2013;44(3):302-307) @ 2013 American Journal of Preventive Medicine

\section{Introduction}

$\eta$ he beginning of this century was characterized by a change in the field of cognitive enhancement strategies, with growing interest in compensatory techniques-external memory aids. These techniques, such as personal diaries, agendas, timers, and check-lists, described as memory prosthetics, ${ }^{1}$ proved to be effective for improving everyday memory function in people with memory deficits. ${ }^{2}$ However, these aids required a training period, which was considered an obstacle for those individuals who deny their memory difficulties. ${ }^{3}$ Microsoft's SenseCam, ${ }^{4}$ a wearable camera developed by Microsoft Research Cambridge, is a recent addition to the external aids available for memory rehabilitation. It automatically

From the Faculty of Psychology (Silva, Pinho), Center for Informatics and Systems (Macedo), University of Coimbra, Coimbra, Portugal; Institute of Psychological Sciences, University of Leeds, Leeds, United Kingdom (Silva, Moulin); and Laboratoire d'Etude del'Apprentissage et du Développement, LEAD-CNRS (UMR 5022) (Moulin), University of Bourgogne, Dijon, France

Address correspondence to: Ana R. Silva, MSc, Faculty of Psychology, University of Coimbra, Rua do Colégio Novo, 3001-802, Coimbra, Portugal. E-mail: ana.rita.ess@gmail.com.

$0749-3797 / \$ 36.00$

http://dx.doi.org/10.1016/j.amepre.2012.11.005 records pictures of the user's activities that can be reviewed later, with no need for training.

The first clinical studies with SenseCam suggested improvement in autobiographic memory (memory for recent episodes captured on the device) in amnesia. ${ }^{4}$ In brief, SenseCam generates powerful cues that aid remembering and helps the retrieval of episodic information related to the reviewed images. ${ }^{5-8}$ SenseCam review improves retrieval of autobiographic information even after time intervals of 2-6 months, suggesting maintenance over long periods. ${ }^{5,9}$ Some studies in healthy adults have aimed to understand the processes underlying this effect. ${ }^{10,11}$ These initial explanations consider that SenseCam pictures mimic episodic memory ${ }^{12}$ because these pictures evoke visual experience, are from an egocentric viewpoint, correspond to reality and make summary records, and thus contribute to a stronger memory trace.

SenseCam has therefore been shown to be efficacious in autobiographic memory (mostly visual data) and personal semantic memory, ${ }^{13}$ and for events and images contained in the SenseCam images. In the current study, the purpose was to examine how SenseCam may stimulate memory more generally. No comprehensive studies have been conducted with SenseCam as a memory aid that involve a detailed neuropsychological assessment 
following its use. One impression gained from anecdotal reports from patients is that SenseCam might stimulate memory function more generally, for domains and materials beyond those captured in the images reviewed.

In the current study, this hypothesis is tested by giving participants a thorough neuropsychological assessment after reviewing SenseCam movies of their daily life, and comparing it, in the same participants, to neuropsychological assessment following re-reading of a diary. Groups of younger and older adults were used to examine how this hypothesis may stand up to group differences in memory function. That is, the focus of this study is on whether SenseCam review improves performance on a series of standardized cognitive tests.

\section{Methods}

A total of 29 participants completed the study. In the young adults group $(n=15)$, the average age was 19 years $(S D=1.9)$, with $65 \%$ female; in the older adults group $(n=14)$, the average age was 75 years $(\mathrm{SD}=5.6)$ and there were an equal number of men and women. In both groups, the mean years of education was 13 $(\mathrm{SD}=2.2)$. The sample size was dictated by the length of time each participant could have a SenseCam, and the availability of SenseCams in the laboratory; to foreshadow the results, the experiment was suitably powered.

The young adults were recruited through a participant pool scheme running in the Psychology Department at the University of Leeds. In the case of the older adults' recruitment, they also were selected from an Older Adults Voluntary Participant Pool at the University of Leeds. This panel is composed of medically fit volunteers who have been screened previously and excluded if they have cognitive function scores below normal cutpoints. Participants were included only if they were native English speakers. All study procedures were approved by the research ethics board of the department. No participants withdrew from the study. All participants provided informed consent and agreed to use SenseCam and the diary for 3 days each. Participants were informed from the beginning of the sessions that after the end of the experiment all the images captured with SenseCam would be provided on a CD, and the diary would be returned.

A mixed design was used, with age as the grouping variable (between-subjects factor) and memory aid as a within-subjects factor (all participants used the two memory aids tested in this experiment). The SenseCam review condition was compared to a written diary (a common memory aid used as a control task). The design was factorial, and the results were yielded to a series of ANOVAs. Data were collected in individual test sessions.

Participants wore the SenseCam and were instructed, before starting to use it, on how to charge it and how to use the buttons (privacy, on/off button, manual trigger). They were instructed to wear the camera for as long as possible each day, but to remove the camera for any events they wanted to keep private. All participants produced 3 days' worth of images to review. After 3 days, they returned to the Institute of Psychological Sciences at Leeds (IPS) and their pictures were downloaded and imported into SenseCam Image Viewer software. ${ }^{4}$

For the diary, participants wrote a page-by-day journal, noting the events they experienced over 3 days. They were instructed to record events in the corresponding day's page as soon as possible after their occurrence but without letting the diary influence their regular behavior. The diaries were not scored, but each participant complied with the instructions given and produced at least four descriptions of personal events for each day. After 3 days with the diary, participants returned to IPS and were asked to read in the session the information they wrote in the diary. Because the emphasis was on the act of review on unrelated neuropsychological tasks, the content of people's diaries and SenseCam movies was not analyzed or classified.

Participants used one of the memory aids (SenseCam or diary) in a counterbalanced fashion for 3 days and returned for an individual session of neuropsychological assessment. In the assessment session, participants first reviewed the contents of their memory aid, and then immediately underwent a comprehensive neuropsychological assessment. In terms of review, for the SenseCam condition, the participants were shown the pictures captured by the device over the 3 days. In the diary condition, the participants were presented with the pages of the diary that they wrote during the 3 days.

A battery of neuropsychological tasks (Table 1) was selected on the basis that they had alternate forms (i.e., it was possible to use

\section{Table 1. Neuropsychological tasks}

\begin{tabular}{|c|c|}
\hline $\begin{array}{l}\text { California Verbal } \\
\text { Learning Test-II } \\
\left(\mathrm{CVLT}^{14}\right)\end{array}$ & $\begin{array}{l}\text { Participants are asked to memorize a } \\
\text { 15-item list, which is repeatedly } \\
\text { presented and tested across five } \\
\text { trials. There are measures of recall } \\
\text { and recognition. This is a classic } \\
\text { measure of verbal episodic memory. }\end{array}$ \\
\hline $\begin{array}{l}\text { Month ordering } \\
\left(\mathrm{MO}^{15}\right)\end{array}$ & $\begin{array}{l}\text { Participants hear the names of a set } \\
\text { of months, and they have to } \\
\text { memorize them and organize them } \\
\text { into the right order, before repeating } \\
\text { them to the experimenter. This is a } \\
\text { test of working memory. }\end{array}$ \\
\hline $\begin{array}{l}\text { Verbal fluency test } \\
\left(\mathrm{VF}^{16}\right)\end{array}$ & $\begin{array}{l}\text { Participants are asked to produce as } \\
\text { many words as possible beginning } \\
\text { with a given letter (e.g., F, A, S) or } \\
\text { category (animals, occupations) in } 1 \\
\text { minute. This is a test of executive } \\
\text { function. }\end{array}$ \\
\hline $\begin{array}{l}\text { Symbol Search } \\
\text { and Coding } \\
\left(\mathrm{SSC}^{17}\right)\end{array}$ & $\begin{array}{l}\text { Participants are given a symbol to } \\
\text { detect among an array of similar } \\
\text { symbols. The time taken to detect } \\
\text { and cancel each symbol is } \\
\text { measured (symbol search). } \\
\text { Participants also recode a sequence } \\
\text { of symbols using a given number } \\
\text { code (symbol coding). These are } \\
\text { measures of speed of processing. }\end{array}$ \\
\hline $\begin{array}{l}\text { Autobiographical } \\
\text { Memory Test } \\
\left(\mathrm{AMT}^{18} \text { ) }\right.\end{array}$ & $\begin{array}{l}\text { Participants retrieve information from } \\
\text { their own life, cued by words such } \\
\text { as "dog," and "happy." The } \\
\text { experimenter rates the specificity of } \\
\text { the memories generated according } \\
\text { to a standardized scale. }\end{array}$ \\
\hline $\begin{array}{l}\text { Digit Span task } \\
\text { (DST }^{19} \text { ) }\end{array}$ & $\begin{array}{l}\text { Participants are presented with a } \\
\text { sequence of digits that they must } \\
\text { memorize and then repeat } \\
\text { immediately to the examiner, either } \\
\text { in the same order (digits forward) or } \\
\text { the reverse order (digits backward). }\end{array}$ \\
\hline
\end{tabular}


them meaningfully at two time points). The neuropsychological tests given were: California Verbal Learning test-II, ${ }^{14}$ month ordering, ${ }^{15}$ verbal fluency test, ${ }^{16}$ symbol search and coding, ${ }^{17}$ autobiographic memory test, ${ }^{18}$ and digit span task. ${ }^{19}$ These tests are used routinely by psychologists in clinical settings for cognitive assessment. Older adults were screened for dementia using the Addenbrooke's Cognitive Examination-Revised. ${ }^{20}$

Participants also were asked to evaluate their memory and the use of the two memory aids by administering a multiple-choice questionnaire. In this questionnaire, participants were asked to rate their memory (on a scale) after using SenseCam or the diary. They rated the impact of watching the memory aids to prompt more memories, and several feelings following review of the diary and SenseCam images: surprise, excitement, alertness, and emotional impact. They also rated the sense that the memory aid was helpful in remembering forgotten information; and the experience of reliving the events. These ratings were all given on a 6-point scale. The results were yielded to a series of ANOVAs for a comparison of the two memory aids. Data for this study were collected from October to December 2011 and analyzed from January to March 2012.

\section{Results}

All analyses were performed in SPSS, version 19. The critical comparison was whether neuropsychological test performance was higher following SenseCam review compared to re-reading the diary (Table 2). The two age groups also were compared. The strategy was the same for each of the separate neuropsychological test scores; to compare test performance in a $2 \times 2$ (age group $\mathrm{X}$ memory aid) ANOVA. For conciseness, the focus here is on describing the main effects of the memory aid (but full ANOVA terms are provided in Table 2 for completeness).

Table 2 presents the $F$-ratios and partial eta-square as effect size (for the main effect of memory aid only). Most measures show a significantly higher performance in the SenseCam condition (tasks that tested verbal memory, semantic memory, working memory, and executive functions). Only two measures yielded a nonsignificant main effect of memory aid ( $p>0.05)$ : the speed of processing measures (symbol search/coding). In most of the tests, younger adults have superior performance compared to older adults, as is usual in the memory literature. ${ }^{21}$

Only one interaction was found: on the autobiographic memory test task, older adults improved more than the younger group with SenseCam, $F(27)=9.213, p<0.001$, $\varepsilon^{2}=0.25$. However, the effects of SenseCam review were parallel in the two groups. This interaction was examined using paired samples $t$ tests to examine whether each group showed an effect of SenseCam review, in line with the key hypothesis. This analysis revealed significant effects in both the young, $t(14)=8.071, p<0.01$, and older adult, $t(13)=8.090, p<0.01$, groups.

The subjective experience of the memory aids might begin to explain the mechanisms behind these findings (Table 3). The subjective data are in line with the objective data collected, with SenseCam review rated as prompting more memories than the diary. SenseCam use also led to

Table 2. Neuropsychological assessment, by age group and memory aid, M (SD) unless otherwise noted

\begin{tabular}{|c|c|c|c|c|c|c|c|c|}
\hline \multirow[b]{2}{*}{ Cognitive test ${ }^{a}$} & \multicolumn{2}{|c|}{ Older adults } & \multicolumn{2}{|c|}{ Younger adults } & \multirow{2}{*}{$\begin{array}{c}\text { Main effect of } \\
\text { memory aid } \\
(F \text { statistic }) \\
\text { df }=1.27\end{array}$} & \multirow{2}{*}{$\begin{array}{l}\text { Main effect of } \\
\text { age group } \\
\text { (F statistic) }\end{array}$} & \multirow{2}{*}{$\begin{array}{l}\text { Interaction effect } \\
\text { of memory aid } X \\
\text { group ( } F \text { statistic) }\end{array}$} & \multirow{2}{*}{$\begin{array}{l}\text { Memory aid } \\
\text { effect size, } \varepsilon^{2}\end{array}$} \\
\hline & SenseCam & Diary & SenseCam & Diary & & & & \\
\hline AMT & $19.07(1.38)$ & 12.57 (3.81) & $19.22(1.15)$ & 15.99 (3.33) & $127.05^{*}$ & $6.327^{*}$ & $\begin{array}{c}9.213^{*} \\
\varepsilon^{2}-0.25^{\mathrm{b}}\end{array}$ & 0.82 \\
\hline CVLT (immediate) & 13.99 (2.26) & $12.43(2.03)$ & $15.07(1.34)$ & $13.80(1.01)$ & $17.22^{*}$ & $5.729^{*}$ & 0.020 & 0.29 \\
\hline CVLT (short delay) & $12.64(3.27)$ & $10.64(3.20)$ & $14.33(1.63)$ & $12.33(2.02)$ & $19.31^{*}$ & $3.906^{*}$ & 0.001 & 0.42 \\
\hline CVLT (long delay) & $13.14(2.79)$ & $11.36(2.87)$ & $14.80(1.02)$ & $12.13(1.64)$ & $37.38^{*}$ & $4.464^{*}$ & 1.363 & 0.58 \\
\hline CVLT (recognition) & $14.86(1.51)$ & $13.29(3.02)$ & $15.73(0.46)$ & 15.01 (1.01) & $9.102^{*}$ & $6.433^{*}$ & 2.214 & 0.25 \\
\hline Month ordering & 14.07 (1.14) & $12.36(1.98)$ & $14.53(0.99)$ & $13.53(1.06)$ & $22.92^{*}$ & $3.964^{*}$ & 1.587 & 0.46 \\
\hline Digit span & 21.64 (2.87) & $19.64(4.44)$ & 20.27 (2.91) & 17.87 (3.09) & $25.99^{*}$ & $3.785^{*}$ & 0.215 & 0.49 \\
\hline Phonemic fluency & $59.42(11.9)$ & 52.00 (14.07) & $53.00(12.2)$ & 44.13 (10.68) & $21.04^{*}$ & $3.965^{*}$ & 0.202 & 0.43 \\
\hline Semantic fluency & $39.85(6.53)$ & 34.50 (7.59) & $38.13(3.40)$ & $34.53(4.42)$ & $32.76^{*}$ & $3.186^{*}$ & 1.261 & 0.55 \\
\hline Symbol search & 26.71 (6.09) & $29.07(7.22)$ & $43.27(3.43)$ & 41.93 (3.90) & 0.266 & $73.270^{*}$ & 2.456 & 0.01 \\
\hline Coding & 57.29 (9.19) & 59.21 (11.3) & $91.13(10.8)$ & $89.20(8.80)$ & 0.000 & $91.123^{*}$ & 1.277 & 0.00 \\
\hline
\end{tabular}

Note: Boldface indicates significance.

'For all the standardized measures used to test participants' cognitive function, a higher score corresponds to a better performance on the test.

${ }^{b}$ Effect size for the interaction effect in AMT

*Significance $\leq 0.05$ indicates the mean results of the variables analyzed are statistically different.

AMT, Autobiographic Memory Test; CVLT, California Verbal Learning Test 
Table 3. Subjective experience ratings, by age group and memory aid ${ }^{a}$

\begin{tabular}{|c|c|c|c|c|c|c|c|}
\hline \multirow{2}{*}{$\begin{array}{l}\text { Subjective } \\
\text { experience }\end{array}$} & \multicolumn{2}{|c|}{ Older adults } & \multicolumn{2}{|c|}{ Younger adults } & \multirow{2}{*}{$\begin{array}{l}\text { Main effect of } \\
\text { memory aid } \\
\text { ( } F \text { statistic), } \\
\text { df }=1,27\end{array}$} & \multirow{2}{*}{$\begin{array}{l}\text { Main effect of } \\
\text { age group } \\
\text { ( } F \text { statistic) }\end{array}$} & \multirow{2}{*}{$\begin{array}{l}\text { Memory aid } \\
\text { effect size, } \varepsilon^{2}\end{array}$} \\
\hline & SenseCam & Diary & SenseCam & Diary & & & \\
\hline Prompting memories ${ }^{\mathrm{b}}$ & $0.93(0.61)$ & $0.50(0.52)$ & $1.53(0.64)$ & $0.80(0.41)$ & 18.38 & 8.53 & 0.45 \\
\hline Surprise $^{c}$ & $3.29(1.32)$ & $1.86(1.01)$ & $4.40(0.83)$ & $2.33(0.98)$ & 43.94 & 7.21 & 0.62 \\
\hline Excitement $^{\mathrm{C}}$ & $3.71(1.38)$ & $1.86(1.23)$ & $4.13(0.64)$ & $2.04(1.06)$ & 46.77 & 2.23 & 0.65 \\
\hline Alert $^{\mathrm{C}}$ & $3.79(1.12)$ & $2.21(1.46)$ & $4.07(0.46)$ & $3.33(0.82)$ & 15.19 & 8.40 & 0.36 \\
\hline Emotion $^{c}$ & $2.31(1.71)$ & $1.86(1.22)$ & $3.33(1.23)$ & $2.07(1.10)$ & 8.07 & 2.60 & 0.23 \\
\hline Helpful $^{\mathrm{C}}$ & $4.50(0.56)$ & $3.86(1.16)$ & $4.40(1.24)$ & $3.87(1.87)$ & 4.17 & 0.03 & 0.13 \\
\hline Reliving events $^{c}$ & 3.96 (1.17) & 2.29 (1.44) & $4.47(0.74)$ & 2.60 (1.24) & 22.85 & 3.29 & 0.46 \\
\hline
\end{tabular}

Note: Boldface indicates significance.

${ }^{a}$ Example of a question from this questionnaire: How did it feel to review the diary/SenseCam images? (please indicate how strongly you agree with each statement, where 1 [one] indicates strongly agree and 5 [five] indicates strongly disagree). . . It felt exciting to review those three days." Participants were tested about their subjective experiences with this questionnaire at the end of each condition (diary/SenseCam).

${ }^{\mathrm{b}}$ Rating scale: $0=$ did not prompt any more memories; $1=$ prompted a few more memories; 2 =prompted a lot of more memories

${ }^{\mathrm{c}}$ Rating scale from 1 to 6 , with 1 meaning absence of that subjective experience and 6 meaning complete presence of that subjective experience

higher reports of surprise and alertness compared to the diary review. In all, both groups agreed that SenseCam was a more exciting memory aid to work with; was more helpful (if they wish to remember something they have forgotten); and makes them feel more emotional than reading the personal diary. Finally, participants from the two groups agreed that SenseCam produces a sense of reliving the moments recorded in the pictures, which was not reported with review of the diary.

\section{Discussion}

This study tested whether previously reported improvements in recall of events following the review of SenseCam images generalized to the improvement of cognitive performance. First, the results extend previous findings that show SenseCam improves autobiographic memory by cueing events continued in the images. ${ }^{5,7,8}$ It was found that SenseCam also improves performance, relative to a diary condition, on a measure of autobiographic memory for events not captured in the SenseCam images. The autobiographical memory test concerns the whole life span, not just the limited content of the SenseCam or diary period. Thus, SenseCam review appears to improve the specificity and level of detail of autobiographic memory from across the life span.

Second, an effect of SenseCam is present in domains other than autobiographic memory as evidenced by a superior performance in tasks that tested learning a list of words (California Verbal Learning Test), as well as the brief registration of digits and reordering months (classic tests of working memory and executive function) and also the generation of category exemplars (a measure of semantic memory). This research suggests that SenseCam may operate as a cognitive stimulant in daily life for a healthy population. Further research should attempt to clarify what aspect of SenseCam review leads to this effect. Is it the review of any pictures that is stimulating? Could it be the emotional effect of using a novel gadget? The authors tentatively suggest that this effect of SenseCam review could stem from the fact that neuroimaging studies have shown it to produce pronounced activation in the hippocampus, an area of the brain critical for memory function. ${ }^{10}$

However, the subjective report in the final questionnaire may be useful for the understanding of the basis of the SenseCam effect. These ratings suggest that the improvement in cognitive function may be related to the feelings of alertness, and the pleasure of using the device. Indeed, previous research has shown that using technology to assist cognition is motivating ${ }^{23}$ and contributes to a stronger feeling of self-efficacy and an improved mood. ${ }^{24}$

On the other hand, the fact that SenseCam is a passive assistive technology for cognition may explain why the effect worked equally for old and younger adults. Even though older adults had poorer performance overall, they still benefited from review of pictures. This is possibly because review does not require the intentional processes that decline with age. ${ }^{25}$ These are, however, provisional suggestions about the processes underlying the effect seen here, which the authors will try to clarify with forthcoming experiments.

To put these results in context, a recent review of memory training in aging ${ }^{26}$ stated that the focus must be 
put on compensatory strategies more than on internal strategies. Also, the compensatory strategies must be user-friendly, and require as little training as possible, so that the compensatory overactivation can occur and promote effects that improve cognitive performance among older adults. The authors of the current study consider the current results to be in accordance with this perspective. The critical issue is now to evaluate this kind of compensatory memory aid over longer periods of time, so that its long-term effectiveness and usability can be gauged.

\section{Limitations}

Although this study produced some large effect sizes on standardized measures of function, this experiment was run with a convenience-based sample, with participants who were motivated to use SenseCam. The fact that only a healthy population was tested in this study is also a constraint. Consequently, it is still unknown whether this general benefit of SenseCam to participants without cognitive problems would extend to patients with memory deficits.

Most critically, the effect here is immediate, and possibly short-term. Thus, the aim of the authors' larger research program is to address these limitations by examining the generalization of the effect of SenseCam to other cognitive areas in a clinical sample (patients with mild Alzheimer's disease). In this larger investigation, a more complete cognitive assessment battery will be administered and SenseCam will be tested for longer periods of time in patients, with a baseline, a post-intervention, and a follow-up assessment.

\section{Conclusion}

To date, research with devices such as SenseCam has focused on the use of technologies as compensatory aids for memory. This view emphasized "cognitive prosthetics" because they were considered to act as a substitute for cognitive function following impairment. This idea has dominated the field of memory aids in general ${ }^{1}$ and new technologies in particular. ${ }^{22}$ This study provides a novel perspective showing stimulation of cognition following SenseCam review. This finding suggests that review of SenseCam images does more than just support or compensate for failing memory; it may act to actually improve it. Because SenseCam is a passive memory aid, with no need for training, if its efficacy in delaying the appearance of symptoms associated with neurodegenerative diseases could be proven, it has the potential to substantially reduce the resources normally required to treat these kinds of conditions.

This work was carried out at the Institute of Psychological Sciences, University of Leeds, United Kingdom.

The research for this article was supported by the Fundacão para a Ciência e Tecnologia (Portuguese Foundation for Sci- ence and Technology; SFRH/BD/68816/2010) for the first author (PhD Fellowship).

CJM is supported by a research donation from Microsoft Research Cambridge to cover the travel expenses associated with presenting research about SenseCam in a series of seminars (2011-2012). No other financial disclosures were reported by the authors of this paper.

\section{References}

1. Kapur N, Glisky EL, Wilson BA. External memory aids and computers in memory rehabilitation. In: Baddeley AD, Kopelman MD, Wilson BA, eds. Handbook of memory disorders. 2nd ed. Chichester, UK: Wiley, 2002.

2. Intons-Peterson MJ, Newsome GL III. External memory aids: effects and effectiveness. In: Herrmann D, Weingartner H, Searleman A, McEvoy C, eds. Memory improvement: implications for memory theory. New York: Springer-Verlag, 1992.

3. Lee M, Dey A. Capturing and reviewing context in memory aids. Workshop on Designing Technology for People with Cognitive Impairments; 2006.

4. Hodges S, Williams L, Berry E, et al. SenseCam: a retrospective memory aid. In: Dourish P, Friday A, eds. Ubicomp 2006 LNCS, Vol. 4206. Berlin: Springer-Verlag, 2006.

5. Berry E, Kapur N, Williams L, et al. The use of a wearable camera SenseCam as a pictorial diary to improve autobiographical memory in a patient with limbic encephalitis. Neuropsychol Rehabil 2007;17: 582-681.

6. Lee M, Dey A. Providing good memory cues for people with episodic memory impairment, ASSETS 2007. Tempe AZ: ACM Press.

7. Browne G. SenseCam and memory rehabilitation. British Psychological Society National PSIGE Conference - Special Interest Group for Psychologists working with Older People; Nottingham, UK; 2007.

8. Loveday C, Conway M. Using SenseCam with an amnesic patient: accessing inaccessible everyday memories. Memory 2011;19(7):697704.

9. Baecker R, Ptak D. The cognitive and psychosocial impact of two SenseCam media formats on persons with cognitive impairments. SenseCam 2010. Dublin, Ireland: Microsoft Research Cambridge.

10. St. Jacques PL, Conway MA, Cabeza R. Gender differences in autobiographical memory for everyday events: retrieval elicited by SenseCam images versus verbal cues. Memory 2011;19:723-32.

11. Ptak R, Van der Linden M, Schnider A. Cognitive rehabilitation of episodic memory disorders: from theory to practice. Front Hum Neurosci 2010;4(57):1-11.

12. Conway M. Memory and the self. J Mem Lang 2005;53:594-628.

13. Pauly-Takacs K, Moulin C, Estlin E. SenseCam as a rehabilitation tool in a child with anterograde amnesia. Memory 2011;19(7):705-12.

14. Delis D, Kaplan E, Kramer J, Ober B, eds. California Verbal Learning Test-II. San Antonio TX: Psychological Corporation, 2000.

15. Almor A, Kempler D, MacDonald M, Andersen E, Tyler L. Why do Alzheimer's patients have difficulty with pronouns? Working memory, semantics, and pronouns in Alzheimer's disease. Brain Lang 1999; 67:202-27.

16. Mitrushina M, Boone K, Razani J, D’Elia L, eds. Handbook of normative data for neuropsychological assessment. 2nd ed. New York: Oxford University Press, 2005

17. Wechsler D. Wechsler Adult Intelligence Scale-Fourth Edition. San Antonio TX: Pearson, 2008.

18. Williams J, Broadbent K. Autobiographical memory in suicide attempters. J Abnorm Psychol 1986;95:144-9. 
19. Wechsler D. Wechsler Memory Scale-4th ed, technical and interpretive manual. San Antonio TX: Pearson, 2009.

20. Mioshi E, Dawson K, Mitchell J, Arnold R, Hodges J. The Addenbrooke's Cognitive Examination Revised (ACE-R): a brief cognitive test battery for dementia screening. Int J Geriatr Psychiatry 2006; 21(11):1078-85.

21. Naveh-Benjamin M. Adult age differences in memory performance: tests of an associative deficit hypothesis. J Exp Psychol Learn Mem Cogn 2000;26:1170 - 87.

22. Cole E. Cognitive prosthetics: an overview to a method of treatment. Neurorehabilitation 1999;12:39-51.
23. Scherer M, Hart T, Kirsch N, Schulthesis M. Assistive technologies for cognitive disabilities. Crit Rev Phys Rehabil Med 2005;17(3):195-215.

24. Gillespie A, Best C, O'Neill B. Cognitive function and assistive technology for cognition: a systematic review. J Int Neuropsychol Soc 2012; 18:1-19.

25. Park D, Gutchess A, Meade M, Stine-Morrow E. Improving cognitive function in older adults: nontraditional approaches. J Gerontol 2007;62b(1):45-52.

26. Lustig C, Shah P, Seidler R, Reuter-Lorenz P. Aging, training and the brain: a review and future directions. Neuropsychol Rev 2009;19(4): $504-22$. 